\title{
Cavitation patterns in high-pressure homogenization nozzles with cylindrical orifices: Influence of mixing stream in Simultaneous Homogenization and Mixing
}

\author{
V. Gall ( $₫)$, E. Rütten, H. P. Karbstein \\ Food Process Engineering, Karlsruhe Institute of Technology (KIT), 76131 Karlsruhe, Germany
}

\begin{tabular}{|c|c|}
\hline Abstract & Keywords \\
\hline $\begin{array}{l}\text { High-pressure homogenization is the state of the art to produce high-quality emulsions with } \\
\text { droplet sizes in the submicron range. In simultaneous homogenization and mixing (SHM), an } \\
\text { additional mixing stream is inserted into a modified homogenization nozzle in order to create } \\
\text { synergies between the unit operation homogenization and mixing. In this work, the influence } \\
\text { of the mixing stream on cavitation patterns after a cylindrical orifice is investigated. Shadow- } \\
\text { graphic images of the cavitation patterns were taken using a high-speed camera and an } \\
\text { optically accessible mixing chamber. Results show that adding the mixing stream can contribute } \\
\text { to coalescence of cavitation bubbles. Choked cavitation was observed at higher cavitation } \\
\text { numbers } \sigma \text { with increasing mixing stream. The influence of the mixing stream became more } \\
\text { significant at a higher orifice to outlet ratio, where a hydraulic flip was also observed at higher } \sigma \text {. } \\
\text { The decrease of cavitation intensity with increasing back-pressure was found to be identical with } \\
\text { conventional high-pressure homogenization. In the future, the results can be taken into account } \\
\text { in the SHM process design to improve the efficiency of droplet break-up by preventing cavitation } \\
\text { or at least hydraulic flip. }\end{array}$ & $\begin{array}{l}\text { high-pressure homogenization } \\
\text { cavitation } \\
\text { simultaneous homogenization and } \\
\text { mixing (SHM) } \\
\text { shadow-graphic images } \\
\text { orifice } \\
\text { choked flow } \\
\text { hydraulic flip } \\
\text { Article History } \\
\text { Received: } 29 \text { February } 2020 \\
\text { Revised: } 17 \text { September } 2020 \\
\text { Accepted: } 22 \text { September } 2020 \\
\text { Research Article } \\
\text { @ The Author(s) } 2020\end{array}$ \\
\hline
\end{tabular}

\section{Introduction}

High-pressure homogenization is the state of the art to produce high-quality emulsions with droplet sizes in the submicron range in the pharmaceutical, chemical, and food industry. A raw emulsion is compressed to pressures up to 1000 bar or higher and then accelerated through a disruption unit. While different kinds of disruption units such as flat valves or orifice nozzles are used in homogenizers, they all have a strong reduction of the flow cross section in common (Schuchmann, 2016). As a result, disruptive stresses such as elongational stress, shear stress, or turbulent inertial stress causing droplet breakup are induced in laminar, transitional, or turbulent flow (Walstra, 1993; Kelemen et al., 2015).

Furthermore, hydrodynamic cavitation can occur in and after the constriction due to a local pressure drop (Franc and Michel, 2005). It is defined as the spontaneous emergence, growth, and subsequent implosion of vapor filled cavities.
The collapse of cavitation bubbles near a droplet can lead to the formation of a microjet focused at the bubble and cause droplet breakup. The occurrence of cavitation also changes the local flow conditions and effects the hydrodynamic stresses. In previous works, several cavitation patterns were observed in high-pressure homogenization nozzles (Schlender et al., 2015b; Gothsch et al., 2016). Depending on the applied pressures and the ratio of orifice diameter to outlet diameter $\beta$, jet cavitation, choked cavitation, and hydraulic flip were observed. It was found that the cavitation pattern affects the efficiency of droplet breakup in emulsification processes and the occurrence of a hydraulic flip proved to be especially harmful for the droplet breakup (Schlender et al., 2015b). By applying a back-pressure after the orifice at the same inlet pressure, visible cavitation decreases. This correlation was first shown by McKillop et al. (1955). When the ratio of back-pressure to inlet pressure described as Thoma number reaches $0.3<T h<0.5$ depending

$\triangle$ vanessa.gall@kit.edu 


\begin{tabular}{|c|c|c|c|}
\hline$d_{\text {inlet }}$ & diameter of orifice inlet (mm) & $p_{\text {inlet }}$ & pressure at orifice inlet (bar) \\
\hline$d_{\text {orifice }}$ & diameter of orifice (mm) & $p_{2}$ & pressure applied downstream the orifice (bar) \\
\hline$d_{\text {outlet }}$ & diameter of orifice outlet (mm) & $p_{\text {vapor }}$ & vapor pressure (bar) \\
\hline $\mathrm{HPH}$ & high-pressure homogenization & SHM & simultaneous homogenization and mixing \\
\hline$\dot{M}_{\mathrm{HS}}$ & mass flow rate of high-pressure stream $(\mathrm{kg} / \mathrm{s})$ & $T h$ & Thoma number $(-)$ \\
\hline$\dot{M}_{\mathrm{MS}}$ & mass flow rate of mixing stream $(\mathrm{kg} / \mathrm{s})$ & $u_{\mathrm{HS}, \text { inlet }}$ & velocity at orifice inlet $(\mathrm{m} / \mathrm{s})$ \\
\hline$\dot{M}_{\text {total }}$ & total mass flow rate $(\mathrm{kg} / \mathrm{s})$ & $u_{\mathrm{MS}, \text { inlet }}$ & velocity at mixing stream inlet $(\mathrm{m} / \mathrm{s})$ \\
\hline OAMC & optically accessible mixing chamber & $\beta$ & ratio of orifice to outlet diameter $(-)$ \\
\hline$p$ & pressure (bar) & $\sigma$ & cavitation number $(-)$ \\
\hline
\end{tabular}

on the geometry, cavitation disappears (Jahnke, 1998). Amongst others, Kurzhals and Reuter (1979), Freudig et al. (2003), Finke et al. (2014), and Schlender et al. (2015a) were able to enhance droplet breakup efficiency in emulsification trials by applying a back-pressure with a minimum droplet size located at $20 \%-30 \%$ of the inlet pressure.

However, conventional high-pressure homogenization is still very energy consuming and not applicable for some material systems. By adding an additional mixing stream into the homogenization nozzle shortly after the orifice, new applications and energy reductions could be achieved (summarized in Gall et al. (2016)). This development is called simultaneous homogenization and mixing (SHM) (Köhler und Schuchmann, 2012). For example, it can be used to improve energy efficiency in milk homogenization by preventing coalescence by diluting the premix using a mixing stream of skim milk (Köhler et al., 2007). At the present time, it is not fully understood how adding the mixing stream changes the flow conditions in the SHM nozzle. So far, no cavitation investigations have been carried out including a mixing stream. Since adding the mixing stream causes an increase of the total mass flow and could lead to a local increase of pressure, it possibly changes the cavitation pattern if not reduce cavitation intensity. This assumption is supported by the fact that increasing the $T h$ number did not affect the drop size distribution in the SHM process as strongly as in conventional $\mathrm{HPH}$ in milk homogenization (Köhler et al. 2009).

The aim of this work is therefore to investigate the influence of the mixing stream on the occurrence and pattern of cavitation. As a first step, it is examined whether cavitation in SHM can also be prevented by applying the same $T h$ numbers as in conventional high-pressure homogenization. Since applying a back-pressure increases energy consumption in SHM due to the increased pressure needed for conveying the mixing stream, the influence of the mixing stream on cavitation patterns obtained without applying back-pressure is also investigated. Optical investigations of cavitation have been conducted in the past using incident lighting (de Giorgi et al., 2013), laser light induced luminescence combined with mikro-PIV (Gothsch et al., 2016), or via sono-chemiluminescence (Schlender et al., 2016).

The cavitation patterns in this study are observed taking shadow-graphic images using opposing light at several process parameters as presented by Sato et al. (2013). For the trials, a modified homogenization nozzle with optically accessible mixing chamber (OAMC) was built, which enables the visualization of cavitation after the orifice throat.

\section{Theoretical background}

In order to describe the results obtained in this study, several established approaches will be applied. Based on the continuity equation through an orifice, the mean velocity in the orifice $\bar{u}_{\text {orifice }}$ through an orifice with diameter $d_{\text {orifice }}$ is calculated as follows:

$$
\bar{u}_{\text {orifice }}=\frac{\dot{M}_{\mathrm{HS}}}{\pi \cdot\left(\frac{d_{\text {orifice }}}{2}\right)^{2} \cdot \rho_{1}}
$$

In this case, the mass flow rate $\dot{M}_{\mathrm{HS}}$ through the orifice can be experimentally measured and $\rho_{1}$ represents the density of the liquid at experimental conditions. With the dynamic viscosity of the liquid $\eta_{1}$ and $\bar{u}_{\text {orifice }}$, the $R e$ number in the orifice:

$$
R e_{\text {orifice }}=\frac{\rho_{1} \cdot d_{\text {orifice }} \cdot \bar{u}_{\text {orifice }}}{\eta_{1}}
$$

can be calculated to estimate the flow regime.

In high-pressure processes with an increased backpressure, the ratio between the applied back-pressure $p_{2}$ and inlet pressure $p_{\text {inlet }}$ is often used to describe homogenization results at different parameters (Kurzhals and 
Reuter, 1979). It is defined as Thoma number

$$
T h=\frac{p_{2}}{p_{\text {inlet }}}
$$

In this case, the pressures are given as relative pressures resulting in $T h=0$ describing a process without applied back-pressure. Especially for processes with no or low back-pressure, the cavitation number $\sigma$ is much more precise to describe cavitation patterns. It describes the probability of cavitation appearance in an orifice throat and its outlet channel (Numachi et al., 1960). It is calculated on the basis of the ration between the static pressure tending to suppress cavitation and the hydrodynamic pressure tending to support cavitation (Stanley, 2012):

$$
\sigma=\frac{p_{2}-p_{\text {vapor }}\left(T_{1}\right)}{0.5 \rho_{1} \cdot \bar{u}_{\text {orifice }}^{2}}
$$

Here, $p_{2}$ describes the pressure downstream of the orifice, which equals $p_{2}$ for trials with applied back-pressure and the atmospheric pressure otherwise, and $p_{\text {vapor }}\left(T_{1}\right)$ is given by the vapor pressure for the used liquid at its temperature. While cavitation can initiate when falling below $\sigma=1$, the number of cavitation bubbles and collapses increase with decreasing $\sigma$.

The cavitation number at which the first small cavitation bubbles can be observed is characterized as cavitation inception $\sigma_{i}$, which strongly depends on the geometrical aspects of the orifice described by $d_{\text {outlet }}, d_{\text {orifice }}$, and their ratio $\beta=\frac{d_{\text {orifice }}}{d_{\text {outlet }}}$. Mishra and Peles (2005) measured $\sigma_{\mathrm{i}}=$ $0.1-0.5$ in a micro-orifice with $d_{\text {orifice }}=11.5 \mu \mathrm{m}$ and $\beta=0.1$. With decreasing $\sigma$, more cavitation bubbles occur and expand while traveling downstream with the flow (Sato and Saito, 2002; Mizuyama et al., 2010). When the cavitation bubbles are visible downstream the orifice in the shape of a jet consisting of single bubbles, the cavitation pattern is described as jet cavitation or cavitating jet (Soyama et al., 1996). The cavitation pattern in which the first coherent vapor bubble appears is called chocked cavitation and located at $\sigma_{\mathrm{ch}}$ (Yan and Thorpe, 1990). It can be calculated using the following equations:

$$
\begin{gathered}
\sigma_{\mathrm{ch}}=2 \beta^{4}\left(\frac{1}{C_{\mathrm{c} \cdot \beta^{2}}}-1\right) \\
C_{\mathrm{c}}=\frac{A_{\mathrm{eff}}}{A}
\end{gathered}
$$

The concentration coefficient describes the ratio between the real orifice flow area $A$ and the effective orifice flow area $A_{\text {eff }}$ (Stephan et al., 2019) due to the "vena contracta" at the entrance of the orifice. Choked cavitation can merge into the cavitation pattern "hydraulic flip" by decreasing $\sigma$ or increasing $\beta$ (Schlender et al., 2015b), which occurs when the outlet channel is filled completely by one cohesive vapor bubble surrounded by a thin liquid film (Sou et al., 2007).

\section{Materials and methods}

\subsection{Materials}

Distilled water was used as a model system for both the experiments and simulations. Schlender et al. (2015b) was able to show that adding a surfactant can prevent coalescence of single cavitation bubbles, but does not influence the length and change of cavitation patterns. Their trials also showed that adding plant oil up to $10 \mathrm{wt} \%$ to water with adjusted refractive index showed no influence on the cavitation pattern. Furthermore, the water used in the experiments was not degassed. This could potentially lead to the occurrence of pseudocavitation, which is described as diffusion of dissolved air due to the decrease in local pressure. While Tesch (2002) stated that pseudocavitation plays a minor part at $\sigma \ll 1$, the results observed in this study could present an overlay of pseudocavitation and hydrodynamical cavitation. We decided to work with non degassed distilled water for the following reasons:

- By not degassing the water, the results reflect real process conditions in high-pressure homogenizers better.

- The results presented in this study can be compared to findings in literature (Gothsch et al., 2015; Schlender et al., 2015b).

\subsection{High-pressure homogenization plant setup}

A schematic of the experimental plant setup is given in Fig. 1. For conveying the high-pressure stream, distilled water is prepared in a storage tank (A) and then compressed by a two-piston pump with a working pressure of 1200 bar. A
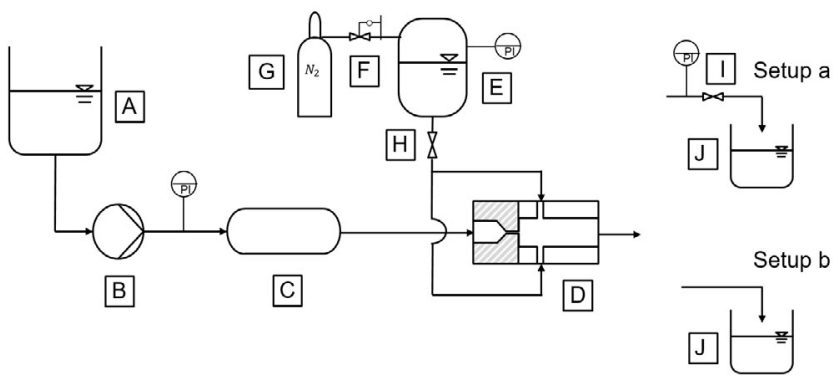

Fig. 1 Experimental plant setup: (A) storage tank high-pressure stream, (B) two-piston pump, (C) pulsation damper, (D) disruption unit, $(\mathrm{E})$ pressure tank, $(\mathrm{F})$ reducing valve, $(\mathrm{G})$ nitrogen tank, $(\mathrm{H})$ needle valve, (I) needle valve, (J) storage-tank outlet stream. The plant can be operated with (setup a) or without (setup b) applying back-pressure with a needle valve. 
pulsation damper $(\mathrm{C})$ compensates for pressure fluctuations. The mixing stream is conveyed by regulating the pressure in a pressure tank (E) with a nitrogen bottle $(\mathrm{G})$ and a reducing valve $(\mathrm{F})$. A needle valve $(\mathrm{H})$ enabled to adjust the mass flow rate of the mixing stream accordingly to the high-pressure stream achieving the desired mixing ratio. Both streams are mixed in a disruption unit with optically accessible mixing chamber (OAMC). The disruption unit is made via drilling and consists of two parts as illustrated in Fig. 1.

The pipe supply of the high-pressure stream and the circular orifice are made of stainless steel to guarantee their pressure resistance. The orifice is followed by an optically accessible mixing chamber (OAMC) made of PMMA (Fig. 2). This design enables the investigation of cavitation after the orifice while cavities in the orifice throat itself remain invisible. The insertion of the mixing stream to the circular outlet is designed as a T-mixer shortly after the orifice. For trails in which cavitation patterns were observed in the outlet channel with $d_{\text {outlet }}=2 \mathrm{~mm}$ and $\frac{\dot{M}_{\mathrm{MS}}}{\dot{M}_{\mathrm{HS}}}=0$, an outlet channel without a T-mixer was used to prevent cavitation bubbles flowing back in and out of the T-mixer and thus changing the cavitation pattern. The geometrical aspects of the disruption unit used for the trials and the simulations are specified in Table 1.

For the trials that required an increased back-pressure after the disruption unit, a needle valve (I) was used (setup a) to reduce the flow cross section. In the remaining trials, the outlet pressure after the orifice $p_{2}$ corresponded to atmospheric pressure.

\subsection{Experimental procedure for capturing shadow-graphic images}

The cavitation patterns were visualized using opposing light imaging (shadow-graphic) as performed in literature (Sato

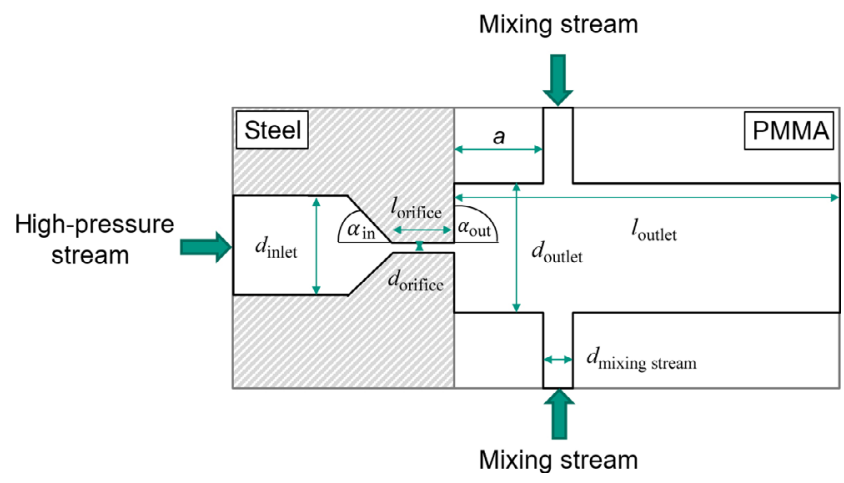

Fig. 2 Schematic diagram of disruption unit consisting of two parts: (1) orifice inlet and throat made of steel, (2) optically accessible mixing chamber made of PMMA.
Table 1 Geometrical aspects of the homogenization unit

\begin{tabular}{ccc}
\hline Geometrical aspect & Abbreviation & \\
\hline Orifice diameter & $d_{\text {orifice }}$ & $150 \mu \mathrm{m}$ \\
Orifice length & $l_{\text {orifice }}$ & $400 \mu \mathrm{m}$ \\
Inlet cone angle & $\alpha_{\text {in }}$ & $59^{\circ}$ \\
Outet cone angle & $\alpha_{\text {out }}$ & $90^{\circ}$ \\
Inlet diameter & $d_{\text {inlet }}$ & $1.5 \mathrm{~mm}$ \\
Diameter of optically accessible unit & $d_{\text {outlet }}$ & $2 \mathrm{~mm} ; 4 \mathrm{~mm}$ \\
Length of optically accessible unit & $l_{\text {outlet }}$ & $40 \mathrm{~mm}$ \\
$\begin{array}{c}\text { Distance between orifice outlet and } \\
\text { mixing stream insertion }\end{array}$ & $a$ & $4.5 \mathrm{~mm}$ \\
\hline
\end{tabular}

et al., 2013; Schlender et al., 2015b). As light source, a LED lamp (Constellation 120 E, IDT Inc., Florida, USA) was installed on the opposite site of the camera. The OAMC was coated with a diffuse film to even out the light. The high-speed camera OS3-S3 (IDT Inc., Florida, USA) combined with a $100 \mathrm{~mm}$ macro objective (Canan Inc., Japan) was used to take pictures of the cavitation patterns in the OAMC. The frequency of the recording was set to $10,000 \mathrm{fps}$ and the exposure time ranged between 50 and $70 \mu$ s. For each set of parameters, 2000 images were taken. Since the cavitating flow fluctuates in time, the image series was converted to gray images in MATLAB (Matlab Inc, USA) and processed to an averaged image. While representative single images are used to discuss the cavitation pattern in detail, the averaged image provides information on the average shape of the cavitation pattern, e.g., the length of the jet in jet cavitation.

In order to investigate the effect of the mixing stream on different cavitation patterns, the inlet pressure $p_{\text {inlet }}$ of the high-pressure stream was varied between 100 and 550 bar. Since the orifice diameter $d_{\text {orifice }}=150 \mu \mathrm{m}$ was kept constant for all trials, an increase of the inlet pressure is directly connected to an increase of the Re numbers in the orifice $R e_{\text {orifice }}$. The values for $R e_{\text {orifice }}$ were calculated and are given in Table 2. However, the discussion of the experiments will be based on the inlet pressures as these contribute to the calculation of the characteristic numbers.

A set of trails was conducted to investigate the influence of an increased $T h$ number on the disappearance of visible cavitation. The Th number was adjusted between 0 (which equals no applied back-pressure) and 0.25. Since the Th number is only commonly used in high-pressure homogenization, the cavitation number $\sigma$ was also calculated for all sets of parameters. For this, the vapor pressure $p_{\text {vapor }}\left(20^{\circ} \mathrm{C}\right)=0.02347$ bar was used (Stephan et al., 2019). In the trials, the temperature ranged between 20 and $40{ }^{\circ} \mathrm{C}$. In that area, the increase of the vapor pressure in this temperature range does barely influence $\sigma$ and was therefore neglected. 
Table 2 Measured mass flow rates and calculated characteristic values

\begin{tabular}{cccccc}
\hline $\begin{array}{c}p_{\text {inlet }} \\
(\mathrm{bar})\end{array}$ & $\begin{array}{c}p_{2} \\
(\mathrm{bar})\end{array}$ & $\begin{array}{c}\dot{M}_{\mathrm{HS}} \\
(\mathrm{kg} / \mathrm{s})\end{array}$ & $\begin{array}{c}\bar{u}_{\text {orifice }} \\
(\mathrm{m} / \mathrm{s})\end{array}$ & $\begin{array}{c}R e_{\text {orifice }} \\
(-)\end{array}$ & $\sigma(-)$ \\
\hline 100 & 0 & 0.00171 & 97.1 & 16,320 & 0.021 \\
100 & 1 & 0.00171 & 97.1 & 16,320 & 0.042 \\
100 & 5 & 0.00171 & 97.0 & 16,320 & 0.128 \\
100 & 10 & 0.00172 & 97.7 & 16,410 & 0.149 \\
100 & 15 & 0.00168 & 95.3 & 16,010 & 0.353 \\
100 & 20 & 0.00170 & 96.5 & 16,220 & 0.452 \\
100 & 25 & 0.00170 & 96.5 & 16,220 & 0.559 \\
100 & 30 & 0.00163 & 92.6 & 15,570 & 0.725 \\
100 & 40 & 0.00150 & 84.9 & 14,270 & 1.141 \\
100 & 50 & 0.00140 & 79.1 & 13,300 & 1.632 \\
150 & 0 & 0.00200 & 113.5 & 19,070 & 0.0154 \\
200 & 0 & 0.00232 & 131.7 & 22,130 & 0.0114 \\
250 & 0 & 0.00262 & 148.7 & 24,990 & 0.0090 \\
300 & 0 & 0.00284 & 161.2 & 27,090 & 0.0076 \\
400 & 0 & 0.00340 & 193.0 & 32,430 & 0.0053 \\
450 & 0 & 0.00362 & 205.2 & 34,480 & 0.0047 \\
500 & 0 & 0.00384 & 217.9 & 36,620 & 0.0042 \\
550 & 0 & 0.00402 & 228.16 & 38,340 & 0.0038 \\
\hline & & & & &
\end{tabular}

As it is to be expected that the effect of the mixing stream strongly depends on the mixing ratio $\frac{\dot{M}_{\mathrm{MS}}}{\dot{M}_{\mathrm{HS}}}$, it was varied between 0 (no mixing stream) and 20. Because the mixing stream is not considered in any of the characteristic numbers, they only depend on $p_{\text {inlet }}$ and $p_{2}$.

Furthermore, the trials were conducted using two outlet diameters $d_{\text {orifice }}$ at 2 and $4 \mathrm{~mm}$, resulting in $\beta=0.075$ and $\beta=0.038$. The reason for this is that the increase of total mass flow with increasing $\frac{\dot{M}_{\mathrm{MS}}}{\dot{M}_{\mathrm{HS}}}$ could affect the cavitation patterns more significant at a lower outlet diameter and therefore higher $\beta$.

\section{Results and discussion}

The results presented in this study show how the mixing stream in SHM nozzles influences cavitation. The first part deals with the question whether applying a back-pressure affects visible cavitation in the same way as described in literature for conventional HPH nozzles. First, shadowgraphic images are taken under variation of the Th number. These results are supplemented by local pressure distributions calculated in simulations in order to assess their validity with regard to predict cavitation. The second part describes in detail how increasing the mixing stream at constant highpressure homogenization stream affects different cavitation patterns and their transitions using shadow-graphic images.

\subsection{Influence of back-pressure on shadow-graphic images}

In order to verify that the effect of decreasing visible cavitation with increasing back-pressure is comparable to conventional high-pressure homogenization, shadow-graphic images were taken at $T h=0-0.25$ for two inlet pressures. Figure 3 visualizes the cavitation pattern obtained for $\beta=0.075$ and $\frac{\dot{M}_{\mathrm{MS}}}{\dot{M}_{\mathrm{HS}}}=1$. It is remarkable that although the cavitation patterns strongly differ at $T h=0$, they appear identical at increased $T h$ numbers.

While the cavitating jet observed at $p_{\text {inlet }}=100$ bar and $T h=0$ decreases in length and diameter for increasing $T h$, the vapor bubble completely filling out the channel for $p_{\text {inlet }}=200$ bar and $T h=0$ also transitions to jet cavitation already at $T h=0.01$. The $T h$ number proves to be decisive for the jet length of visible cavitation bubbles for this set of parameters. At $T h=0.25$ and $\sigma \approx 0.56-0.59$, cavitation bubbles are not longer visible in the OAMC. Due to the invisible orifice throat, the disappearance of visible cavitation bubbles can only be referred to the disappearance of bubbles visible in the OAMC while they could still occur in the orifice throat. These results confirm that cavitation can be reduced by applying a back-pressure in SHM disruption units as already shown for conventional HPH (Schlender et al., 2016).

The reduction of the cavitating jet at $\frac{\dot{M}_{\mathrm{MS}}}{\dot{M}_{\mathrm{HS}}}=1$ was also directly compared to trials in which no mixing stream was added in Fig. 4. In this case, $\beta$ was set to 0.038 .
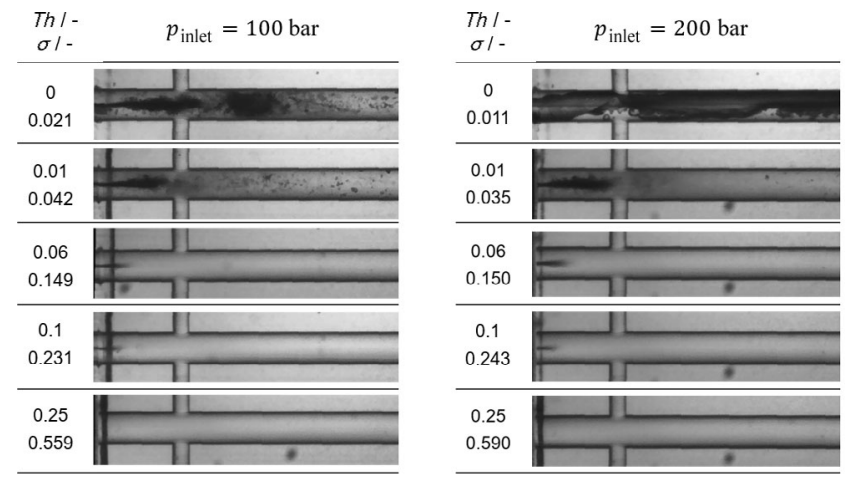

Fig. 3 Influence of back-pressure on supercavitation as a function of inlet pressure and Th for $\beta=0.075$ and $\frac{\dot{M}_{\mathrm{MS}}}{\dot{M}_{\mathrm{HS}}}=1$. The cavitation intensity decreases with increasing Th number and visible cavitation disappears at $T h=0.25$ for both inlet pressures. 


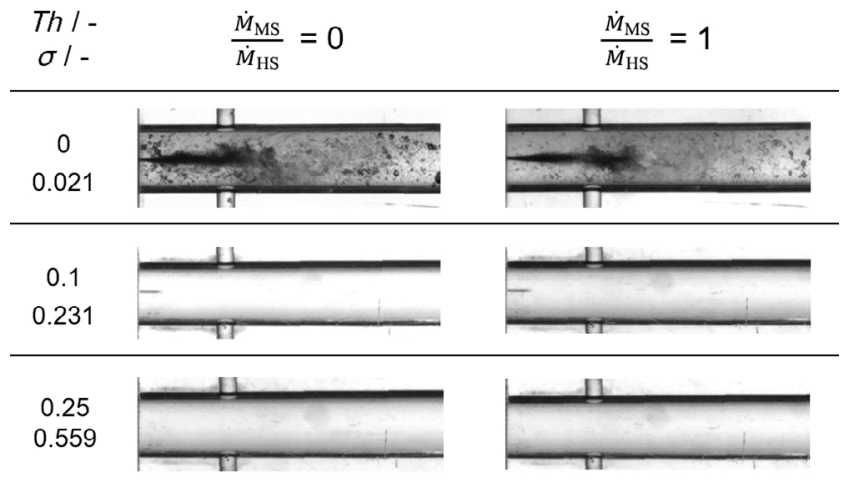

Fig. 4 Influence of back-pressure on visible cavitation as a function of mixing ratio and $T h$ for $\beta=0.038$ and $p_{\text {inlet }}=100$ bar. Adding the mixing stream does not change the visible effect of the applied back-pressure.

With increasing back-pressure, the visible supercavitation in the orifice outlet disappeared at $T h=0.25$ and $\sigma=0.559$. It is clearly visible that the length of the visible cavitating jet at applied back-pressure is not influenced by adding a mixing stream at $\frac{\dot{M}_{\mathrm{MS}}}{\dot{M}_{\mathrm{HS}}}=1$. For this reason, it can be assumed that the values for $T h$ found in literature required for disappearance of visible cavitation are also valid for SHM nozzles. Schlender et al. (2016) observed the disappearance of visible cavitation in shadow-graphic images at $T h=0.28$ using an orifice with a slightly larger diameter of $d_{\text {orifice }}=$ $224 \mu \mathrm{m}$ (Schlender et al., 2016). A comparison with the images shown above also shows that the disappearance of visible cavitation does not depend on $\beta$. In summary, no influence of the mixing ratio could be observed in this case.

\subsection{Influence of mixing ratio on cavitation patterns}

\subsubsection{Influence of mixing ratio on jet cavitation}

This section visualizes the impact on an increasing mixing ratio $\frac{\dot{M}_{\mathrm{MS}}}{\dot{M}_{\mathrm{HS}}}$ on jet cavitation. Figure 5 shows the change of the cavitating jet at $p_{\text {inlet }}=100$ bar and $\beta=0.075$. For a better visibility of the effects, for each mixing ratio ranging between $1 / 5$ and 20, both an instantaneous impression is given by a single image ("instantaneous") and the averaged image shows that the observations are not randomly recorded elves due to the fluctuation of the jet.

The averaged images illustrate that the average length of the jet decreases with increasing mixing ratio between $\frac{\dot{M}_{\mathrm{MS}}}{\dot{M}_{\mathrm{HS}}}=0$ and $\frac{\dot{M}_{\mathrm{MS}}}{\dot{M}_{\mathrm{HS}}}=10$. It should be stated that since $\dot{M}_{\mathrm{HS}}$ remains constant at constant $p_{\text {inlet }}$, the total mass

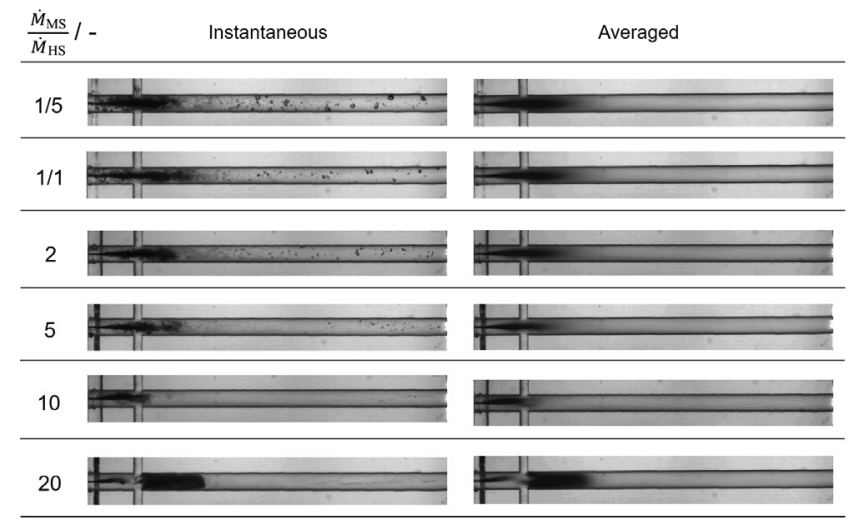

Fig. 5 Influence of increasing mixing ratio on jet cavitation for $\beta=0.075$ and $p_{\text {inlet }}=100$ bar. The cavitating jet increases in length for increasing mixing ratio until a second area of cavitaton is observed.

flow downstream the orifice $\dot{M}_{\text {total }}$ strongly increases with increasing mixing ratio. The instantaneous images also show in this context that single cavitation bubbles that are not dissolved after the orifice are carried out much faster with increasing mixing ratio. The trials do not allow determining whether the decreasing jet length is caused by a local pressure increase due to the insertion of the mixing stream or just a consequence of faster carrying out the cavitation bubbles. In either case, the reducing effect of the mixing ratio on the jet is limited, since the emergence of a second area of cavitation is observed at $\frac{\dot{M}_{\mathrm{MS}}}{\dot{M}_{\mathrm{HS}}}=20$. This effect can most likely be explained by the increase of flow velocity in the outlet channel due to the increase of $\dot{M}_{\text {total }}$. Those effects cannot be described in regard to $\sigma$ since it does not consider the mixing stream.

The effect of the mixing ratio was also investigated at $p_{\text {inlet }}=100$ bar and $\beta=0.038$. The results are displayed in Fig. 6. In this case, both $\dot{M}_{\mathrm{HS}}$ and $\dot{M}_{\text {total }}$ are equal to the flow rates at higher $\beta$, but due to the increased $d_{\text {outlet }}$, the average flow velociy in the outlet channel is much smaller.

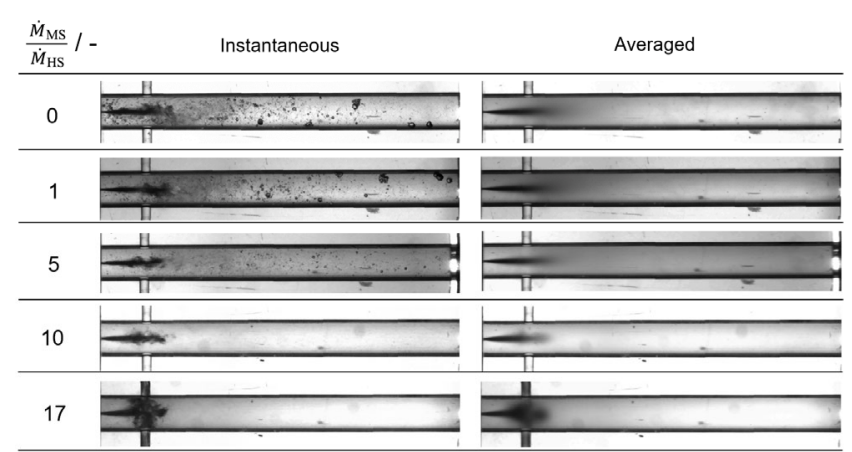

Fig. 6 Influence of increasing mixing ratio on jet cavitation for $\beta=0.038$ and $p_{\text {inlet }}=100$ bar. The cavitating jet is not influenced by the increasing mixing ratio until a second area of cavitaton is observed. 
The images show that the effect of the increased mixing ratio proves to be much smaller than at $\beta=0.078$. The length of the jet cavitation remains constant for mixing ratios up to 5 and is only visible at $\frac{\dot{M}_{\mathrm{MS}}}{\dot{M}_{\mathrm{HS}}}=10$ if at all. For this reason, it can be concluded that the effect of the mixing stream comes into effect stronger when the jet cavitation is already confined by $d_{\text {outlet }}$. For $\frac{\dot{M}_{\mathrm{MS}}}{\dot{M}_{\mathrm{HS}}}=17$, cavitation is also formed in the T-mixer and therefore, two cavitating jets collide where the mixing stream is inserted.

\subsubsection{Influence of mixing ratio on $\sigma_{\mathrm{ch}}$}

With increasing $p_{\text {inlet }}$ or decreasing $\sigma$, more cavitation bubbles are formed which extends the length of jet cavitation. At $\sigma_{\mathrm{ch}}$, the single cavitation bubbles start to coalesce forming a cohesive vapor bubble. Figure 7 illustrates the influence of the mixing ratio on $\sigma_{\mathrm{ch}}$. For trials at $\frac{\dot{M}_{\mathrm{MS}}}{\dot{M}_{\mathrm{HS}}}=0$, the transition to choked cavitation was detected at $p_{\text {inlet }}=450$ bar and $\sigma_{\mathrm{ch}}=0.0047$. During the recording of the image series, the cohesive bubble was periodically formed and carried out. As a result, the cohesive bubble is visible in some of the images (image Nr. 1), while some of the images show a jet consisting of single bubbles (image Nr. 2) as displayed in the top part of Fig. 7. In the averaged picture, this results in a shadow right after the orifice outlet.

For $\frac{\dot{M}_{\mathrm{MS}}}{\dot{M}_{\mathrm{HS}}}=1$, choked cavitation already occurs at $p_{\text {inlet }}$ $=400 \mathrm{bar}$ and $\sigma_{\mathrm{ch}}=0.0053$. The shadow-graphic images in Fig. 7 do not indicate a further increase of $\sigma_{\mathrm{ch}}$ beyond doubt, while the averaged picture shows a hint of a cohesive vapor bubble just being formed at $p_{\text {inlet }}=300$ bar. It is remarkable that the vapor bubble is always oriented to the bottom half of the OAMC. The reason for this could be small irregularities in the nozzle geometry due to its mechanical production. In literature, the transition of $\sigma_{\mathrm{ch}}$ was also observed for increasing $\beta$ (Schlender et al., 2015b).

\subsubsection{Influence of mixing ratio on hydraulic flip}

Since the shadow-graphic images presented in the last section displayed that adding the mixing stream contributed to coalescence of the cavitation bubbles, this section deals with the question whether the mixing stream also affects the hydraulic flip. In Fig. 8, shadow-graphic images for $p_{\text {inlet }}=$ 150-250 bar and $\frac{\dot{M}_{\mathrm{MS}}}{\dot{M}_{\mathrm{HS}}}=0$ and 1 are shown.

The images which were taken without adding a mixing stream for comparison purposes show jet cavitation for $p_{\text {inlet }}=150$ bar. The cavitation pattern at $p_{\text {inlet }}=200$ bar cannot be distinguished without doubt between jet cavitation and choked cavitation. At $p_{\text {inlet }}=250$ bar and $\sigma_{\text {ch }}=0.009$, the hydraulic flip has already occurred. Schlender et al. (2015b)

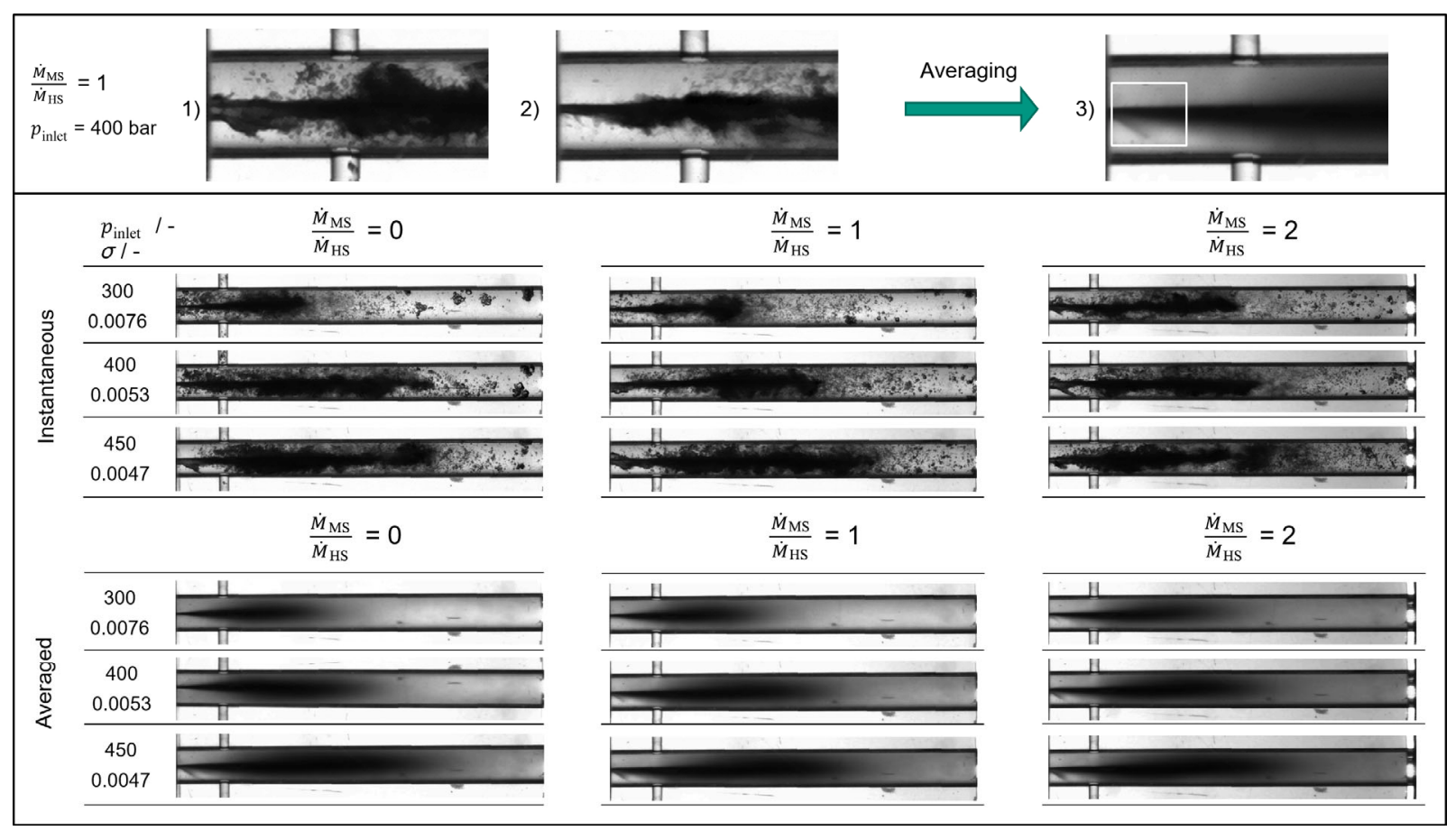

Fig. 7 Influence on mixing ratio on $\sigma_{\mathrm{ch}}$ for $\beta=0.038$. The increase of the mixing ratio causes choked cavitation to occur at higher $\sigma_{\mathrm{ch}}$. 


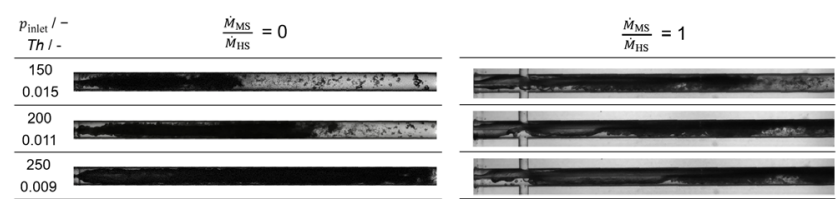

Fig. 8 Influence of mixing stream on hydraulic flip at $\beta=0.075$. The mixing stream provokes an hydraulic flip at lower $p_{\text {inlet }}$.

observed the occurrence of choked cavitation for $\beta=0.075$ at $\sigma_{\mathrm{ch}}=0.0131$, which is in very good agreement to the results presented in this paper. The addition of the mixing stream at $\frac{\dot{M}_{\mathrm{MS}}}{\dot{M}_{\mathrm{HS}}}=1$ causes the hydraulic flip to happen already at $p_{\text {inlet }}=150 \mathrm{bar}$. Since the outlet channel is completely filled with a cohesive vapor bubble, a further increase of $p_{\text {inlet }}$ has no visible effects. Although the change in $\sigma_{\text {ch }}$ could not be detected directly for the parameters examined, the results include the conclusion that $\sigma_{\mathrm{ch}}$ has also increased at $\beta=0.075$.

For $\beta=0.038$, a transition of the hydraulic flip to lower $p_{\text {inlet }}$ could not been detected as shown in Fig. 9. In this case, the cavitation patterns are not affected by varying $\frac{\dot{M}_{\mathrm{MS}}}{\dot{M}_{\mathrm{HS}}}$ between 0 and 2 . In conclusion, the results show that adding the mixing stream can promote the transition of jet cavitation to chocked cavitation as well as the occurrence of the hydraulic flip. It therefore affects the cavitation patterns in a similar way as an increase of $\beta$. It is thus likely that the effect can be counteracted by decreasing $\beta$.

Since a further increase of $\frac{\dot{M}_{\mathrm{MS}}}{\dot{M}_{\mathrm{HS}}}$ leads to a reduction of jet cavitation for $\beta=0.075$, shadow-graphic images were also taken at $\frac{\dot{M}_{\mathrm{MS}}}{\dot{M}_{\mathrm{HS}}}=1,2$, and $p_{\text {inlet }}=200$ bar. The results in

Fig. 10 show that increasing the mixing stream leads to a shorter length of the outlet channel filled with the cohesive vapor bubble. Again, this effect could be ascribed to the fact that the cavitation bubbles are carried out faster.

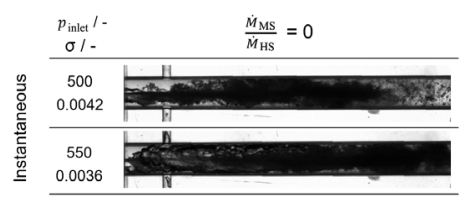

$\frac{\dot{M}_{M S}}{\dot{M}_{\mathrm{HS}}}=0$

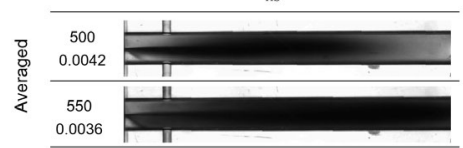

Fig. 9 Influence of mixing stream on hydraulic flip at $\beta=0.038$. The mixing stream does not influence the cavitation pattern in this case.

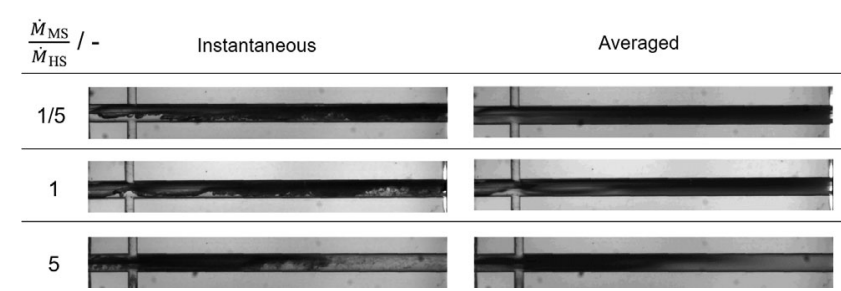

Fig. 10 Influence of mixing ratio on the cavitation pattern at $\beta=0.075$ and $p_{\text {inlet }}=200$ bar.

\section{Conclusions}

In this work we investigated the influence of a mixing stream on cavitation in the disruption unit of a high-pressure homogenizer. It was shown that the mixing stream does not change the $T h$ numbers required to reduce cavitation by applying a back-pressure. Therefore, Th numbers found in literature for conventional high-pressure homogenization can be applied to SHM nozzles in order to suppress cavitation.

In addition, our investigations could show that increasing the mixing ratio of mixing stream to high-pressure stream can cause the cavitation bubbles in jet cavitation to coalesce at higher cavitation numbers $\sigma$ and therefore increase $\sigma_{\mathrm{ch}}$ where choked cavitation is first observed. The increase of the mixing stream can therefore have a similar effect than an increase of the ratio $\beta$ of outlet diameter to orifice diameter. In literature, hydraulic flip is described to be harmful for droplet breakup in HPH processes. Our results suggest that $\beta$ should be adjusted to counteract the effect of the mixing stream. However, the increase of the outlet diameter could also change the mixing characteristics and thus influence droplet breakup. This should be further investigated in future.

\section{Acknowledgements}

The authors gratefully acknowledge the DFG for financial support within the DFG priority programme SPP 1934 (project number 425332181) "proteins under stress".

\section{Funding note}

Open Access funding enabled and organized by Projekt DEAL.

\section{Declaration of competing interest}

The authors have no competing interests to declare that are relevant to the content of this article.

\section{References}

De Giorgi, M. G., Ficarella, A., Tarantino, M. 2013. Evaluating cavitation regimes in an internal orifice at different temperatures using 
frequency analysis and visualization. Int J Heat Fluid $F l, 39$ : 160-172.

Finke, J. H., Niemann, S., Richter, C., Gothsch, T., Kwade, A., Büttgenbach, S., Müller-Goymann, C. C. 2014. Multiple orifices in customized microsystem high-pressure emulsification: The impact of design and counter pressure on homogenization efficiency. Chem Eng J, 248: 107-121.

Franc, J.-P., Michel, J.-M. 2005. Fundamentals of Cavitation. Dordrecht: Springer Science + Business Media Inc.

Freudig, B., Tesch, S., Schubert, H. 2003. Production of emulsions in high-pressure homogenizers - part II: Influence of cavitation on droplet breakup. Eng Life Sci, 3: 266-270.

Gall, V., Runde, M., Schuchmann, H. 2016. Extending applications of high-pressure homogenization by using simultaneous emulsification and mixing (SEM)-An overview. Processes, 4: 46.

Gothsch, T., Richter, C., Beinert, S., Schilcher, C., Schilde, C., Büttgenbach, S., Kwade, A. 2016. Effect of cavitation on dispersion and emulsification process in high-pressure microsystems (HPMS). Chem Eng Sci, 144: 239-248.

Gothsch, T., Schilcher, C., Richter, C., Beinert, S., Dietzel, A., Büttgenbach, S., Kwade, A. 2015. High-pressure microfluidic systems (HPMS): Flow and cavitation measurements in supported silicon microsystems. Microfluid Nanofluid, 18: 121-130.

Jahnke, S. 1998. The theory of high-pressure homogenization. In: Emulsions and Nanosuspensions for the Formulation of Poorly Soluble Drugs. Benita, S., Bohm, B. Eds. CRC Press.

Kelemen, K., Gepperth, S., Koch, R., Bauer, H.-J., Schuchmann, H. P. 2015. On the visualization of droplet deformation and breakup during high-pressure homogenization. Microfluid Nanofluid, 19: 1139-1158.

Köhler, K., Aguilar, F. A., Hensel, A., Schubert, K., Schubert, H., Schuchmann, H. P. 2009. Design of a micro-structured system for the homogenization of dairy products at high fat content part III: Influence of geometric parameters. Chem Eng Tech, 32: 1120-1126.

Köhler, K., Aguilar, F., Hensel, A., Schubert, K., Schubert, H., Schuchmann, H. P. 2007. Design of a microstructured system for homogenization of dairy products with high fat content. Chem Eng Tech, 30: 1590-1595.

Köhler, K., Schuchmann, H. 2012. Simultanes emulgieren und mischen. Chemie Ingenieur Technik, 84: 1538-1544.

Kurzhals, H. A., Reuter, H. 1979. Untersuchungen über Die physikalischtechnischen Vorgänge beim Homogenisieren von Milch in Hochdruck-Homogenisiermaschinen. Chemie Ingenieur Technik, 51: 325 .

McKillop, A. A., Dunkley, W. L., Brockmeyer, R. L., Perry, R. L. 1955. The cavitation theory of homogenization. J Dairy Sci, 38: 273-283.

Mishra, C., Peles, Y. 2005. Cavitation in flow through a micro-orifice inside a silicon microchannel. Phys Fluids, 17: 013601.

Mizuyama, S., Murase, M., Fujii, Y., Yagi, Y. 2010. Detection of cavitation with accelerometers mounted on piping outer surfaces J Environ Eng, 5: 200-212.

Numachi, F., Yamabe, M., O-ba, R. 1960. Cavitation effect on the discharge coefficient of the sharp-edged orifice plate. J Basic Eng, 82: 1-6.

Sato, K., Saito, Y. 2002. Unstable cavitation behavior in a circular- cylindrical orifice flow. JSME International Journal Series B, 45: 638-645

Sato, K., Taguchi, Y., Hayashi, S. 2013. High speed observation of periodic cavity behavior in a convergent-divergent nozzle for cavitating water jet. Journal of Flow Control, Measurement \& Visualization, 1: 102-107.

Schlender, M., Minke, K., Schuchmann, H. P. 2016. Sonochemiluminescence (SCL) in a high-pressure double stage homogenization processes. Chem Eng Sci, 142: 1-11.

Schlender, M., Minke, K., Spiegel, B., Schuchmann, H. P. 2015a. High-pressure double stage homogenization processes: Influences of plant setup on oil droplet size. Chem Eng Sci, 131: 162-171.

Schlender, M., Spengler, A., Schuchmann, H. P. 2015b. High-pressure emulsion formation in cylindrical coaxial orifices: Influence of cavitation induced pattern on oil drop size. Int J Multiphase Flow, 74: 84-95.

Schuchmann, H. P. 2016. Advances in hydrodynamic pressure processing for enhancing emulsification and dispersion. In: Woodhead Publishing Series in Food Science, Technology and Nutrition, Innovative Food Processing Technologies. Knoerzer, K., Juliano, P., Smithers, G. Eds. Woodhead Publishing, 387-412.

Sou, A., Hosokawa, S., Tomiyama, A. 2007. Effects of cavitation in a nozzle on liquid jet atomization. Int J Heat Mass Tran, 50: 3575-3582.

Soyama, H., Yanauchi, Y., Sato, K., Ikohagi, T., Oba, R., Oshima, R. 1996. High-speed observation of ultrahigh-speed submerged water jets. Exp Therm Fluid Sci, 12: 411-416.

Stanley, C. 2012. Experimental investigation of cavitation in a cylindrical orifice. Ph.D. Thesis University of New South Wales.

Stephan, P., Kabelac, S., Kind, M., Mewes, D., Schaber, K., Wetzel, T. 2019. VDI-Wärmeatlas. Fachlicher Träger VDI-gesellschaft Verfahrenstechnik und. MORGAN KAUFMANN (Springer Reference Technik).

Tesch, S. 2002. Charakterisieren mechanischer Emulgierverfahren: Herstellen und Stabilisieren von Tropfen als Teilschritte beim Formulieren von Emulsionen. Ph.D. Thesis. Universität Karlsruhe (TH).

Walstra, P. 1993. Principles of emulsion formation. Chem Eng Sci, 48 : 333-349.

Yan, Y., Thorpe, R. B. 1990. Flow regime transitions due to cavitation in the flow through an orifice. Int J Multiphase Flow, 16: 1023-1045.

Open Access This article is licensed under a Creative Commons Attribution 4.0 International License, which permits use, sharing, adaptation, distribution and reproduction in any medium or format, as long as you give appropriate credit to the original author(s) and the source, provide a link to the Creative Commons licence, and indicate if changes were made.

The images or other third party material in this article are included in the article's Creative Commons licence, unless indicated otherwise in a credit line to the material. If material is not included in the article's Creative Commons licence and your intended use is not permitted by statutory regulation or exceeds the permitted use, you will need to obtain permission directly from the copyright holder.

To view a copy of this licence, visit http://creativecommons.org/licenses/by/4.0/. 